\title{
Sustentabilidade e CTS: o necessário dialógo na/para a Educação em Ciência em tempos de crise ambiental ${ }^{1}$
}

\section{Sustainability and STS: a necessary dialogue in/for Science Education in times of environmental crisis}

\author{
Nadia Magalhães da Silva Freitas* \\ Carlos Alberto Marques**
}

\begin{abstract}
RESUMO
O presente trabalho traz resultados complementares de uma pesquisa anterior, que buscou responder: em que termos se observa a inserção do tema (in) sustentabilidade em trabalhos de teses e de dissertações que se caracterizaram como análise de práticas/ações de Educação em Ciências/Educação Científica e Tecnológica, com enfoque CTS, na abordagem de temas socioambientais. A abordagem sobre sustentabilidade carrega em si a valorização da dimensão ambiental, constituindo-se o core das discussões, especialmente no âmbito educacional, principalmente no contexto das relações CTS. Isso pressupõe ponderar sobre os impactos, por vezes irreversíveis, da exploração da natureza, principalmente sob a égide do capitalismo, o que inexoravelmente envolve o problema da insustentabilidade. Todavia, não se pode restringir a análise em apenas uma das dimensões dos processos insustentáveis, sob o risco de adotarmos uma concepção reducionista e fragmentada, apartada de uma abordagem multidimensional da questão. Em função da vigência de uma crise ambiental, o problema da insustentabilidade assume múltiplas dimensões, com inserção no campo social, econômico, ambiental, ético, entre outros, e sua abordagem tem referência forte nas relações CTS, mas
\end{abstract}

1 Pesquisa financiada pela Coordenação de Aperfeiçoamento de Pessoal de Nível Superior (CAPES).

*Universidade Federal do Pará. Belém, Pará, Brasil. E-mail: nadiamfs@yahoo.com.br. https://orcid.org/0000-0003-0042-8640.

** Universidade Federal de Santa Catarina. Florianópolis, Santa Catarina, Brasil. E-mail: bebetomarques07@gmail.com. https://orcid.org/0000-0002-4024-7695. 
apresenta-se subteorizada principalmente na sua vertente social. Assim, uma abordagem multidimensional das relações CTS na educação em ciências possibilita considerar a (in)sustentabilidade em sua multirreferencialidade de fatores. Ao revelar as convergências destes dois campos "Sustentabilidade e CTS", no campo educacional, estaremos ampliando tanto a visão crítica das relações CTS quanto favorecendo a sensibilidade socioambiental.

Palavras-chave: Sustentabilidade. CTS. Educação em Ciências.

\begin{abstract}
The present work shows complementary results of a previous research that aimed to answer: in what terms could be observed the insertion of the theme (in) sustainability in theses and dissertations that are characterized as analysis of practices/actions of Education in Sciences/Scientific and Technological Education, with STS focus and socio-environmental themes. The sustainability approach carries with it the appreciation of the environmental dimension, being the core of the discussions, especially in the context of STS relations. This presupposes pondering the irreversible impacts of exploitation of nature, especially under the aegis of capitalism, which inexorably involves the problem of unsustainability. However, the analyses can not be restricted to only one of the dimensions of unsustainable processes, with the risk of adopting a reductionist and fragmented approach, apart from a multidimensional approach to the issue. Therefore, due to the existence of an environmental crisis, the problem of unsustainability assumes multiple dimensions, with insertion in the social, economic, environmental and ethical fields, among others, and its approach has a strong reference in STS relations, but it is presented subtheoretically in its social aspect. Thus, a multidimensional approach to STS relationships in science education makes it possible to consider (in) sustainability in its multireferentiality of factors. In revealing the convergences of these two fields "Sustainability and STS", in the educational field, we will be expanding both the critical view of STS relations and favoring socio-environmental sensitivity.
\end{abstract}

Keywords: Sustainability. STS. Science Education.

\title{
Introdução
}

As sociedades contemporâneas vêm passando por profundas transformações, as quais incidem sobre diferentes campos, a saber: social, econômico, ambiental, político, entre outros. Desde o advento da revolução industrial, o 
meio ambiente tem sido palco de intensas ações destrutivas, de modo que ao longo do tempo conformou-se o que hoje é denominado de crise ambiental. Isso tudo parece surgir, como "[...] resultado do desconhecimento da lei da entropia que desencadeou no imaginário economicista uma 'mania de crescimento', de uma produção sem limites" (LEFF, 2010, p. 21).

Assim, a crise ambiental não corresponde a uma mudança natural, mas a uma transformação da natureza impingida pelo homem, pelas suas concepções científicas e tecnológicas do mundo (LEFF, 2010). Acontecimentos como o aumento da produção de resíduos sólidos, o desmatamento, a degradação dos solos, a superexploração de recursos naturais, a poluição de rios e de mares, são algumas das manifestações da crise ambiental (MARQUES, 2015), decorrentes, principalmente, da pressão sobre os recursos naturais, pautados pelo desenvolvimento econômico-produtivista.

É no contexto de apreensões relativas à percepção de que o atual padrão de produção e de consumo, em ampliação no mundo, que não tem possibilidades de persistir (NASCIMENTO, 2012), que se evidencia a emergência da discussão sobre a necessidade de estabelecer um novo paradigma de desenvolvimento. $\mathrm{O}$ desenvolvimento sustentável (DS) tem sido pensado como este novo paradigma de desenvolvimento, cuja definição apresenta-se como aquele capaz de "[...] satisfazer as necessidades das gerações presentes, levando em consideração as necessidades das gerações futuras" (COMISSÃO, 1991, p. 46). Para Moretto e Giacchini (2006, p. 3), o “[...] conceito de desenvolvimento sustentável apresenta-se de forma ampla, envolvendo a questão produtiva, a questão social e a questão ambiental", o que pressupõe a integração das dimensões econômicas, sociais e ambientais, correspondendo aos pilares deste modelo de desenvolvimento (FERREIRA PIMENTA; NARDELLI, 2015; CORREIA; DIAS, 2016).

Em realidade, a apropriação desse conceito se deu em vários domínios da sociedade (FAUSTINO; AMADOR, 2016), encerrando contradições e conflitos (OLIVEIRA, 2012; MELO, 2006). Evidencia-se, também, “[...] múltiplos discursos que ora se opõem, ora se complementam" (NASCIMENTO, 2012, p. 51). No contexto das produções discursivas sobre desenvolvimento sustentável, alguns autores o consideram como falacioso, servindo a propósitos do mercado (CAVALCANTI, 2012). Para outros, o DS “[...] deve ser entendido como um dos mais generosos ideais" (VEIGA, 2015, p. 46), pois acolhe o princípio da solidariedade intergeracional (VEIGA, 2015; CORREIA; DIAS, 2016).

Podemos pensar, a princípio, que o "[...] uso do termo 'sustentável' para qualificar o desenvolvimento sempre exprimiu a possibilidade e a esperança de que a humanidade poderá, sim, se relacionar com a biosfera de modo a evitar os colapsos profetizados [...]" (VEIGA, 2015, p. 46). Consideramos o DS como uma utopia, não no seu sentido quixotesco, mas sim como “[...] visão de futuro 
sobre a qual uma civilização cria seus projetos, fundamentando seus objetivos ideais e suas esperanças" (VEIGA, 2008, p. 14, destaque nosso).

Nesse âmbito, “[...] o desenvolvimento deve ser adequado à ambição de que no longo prazo haja compatibilidade entre a humanidade, os recursos que ela consome e o efeito de suas atividades sobre o meio ambiente" (VEIGA, 2005, p. 5). Essa compatibilidade não desconhece os limites biogeoquímicos da natureza, expressos nas leis termodinâmicas (particularmente a segunda lei - a lei da entropia) (MARQUES; MACHADO, 2014), mas situa essa busca de compatibilidade no âmbito da ética socioambiental que deve orientar todas as práticas sociais, como quando da produção econômica e da ciência.

Portanto, entendemos, assim como Veiga (2008), que o DS se constitui uma ideia-força. Trata-se da busca de um ideal, de modo a gerar novas/outras possibilidades que assumam o desenvolvimento aportado pelos seguintes pressupostos: socialmente justo, ambientalmente prudente e economicamente viável (SACHS, 2002). Compreendemos que, atualmente, a ideia de DS tem caminhado no sentido de "[...] harmonização de objetivos colidentes" (SACHS, 2007, p. 266) e, assim, as discussões e embates se seguem. Entretanto, faz-se necessário caminhar, buscar, de modo que no caminho vislumbremos as possibilidades de mudanças que possam se aproximar desse ideal, mesmo que utópico.

É nesse contexto de discussões, que não podemos nos furtar de tratar os aspectos relacionados à (in)sustentabilidade vinculados às relações Ciência, Tecnologia e Sociedade (CTS), no âmbito educacional, principalmente, como desdobramentos do atual modelo de desenvolvimento, pois se apresentam relevantes e oportunos, ao considerarmos os seguintes argumentos:

[...] 1) o momento socioambiental atual é tenso, quando se considera os limites do planeta; 2) a tecnologia, produto do conhecimento científico, parece não ter sido construída em vinculação a uma ética que indique o sentido e os limites de sua difusão e aplicação no meio social; 3) a educação científica passou por um período de "cegueira" em relação às consequências que o uso do conhecimento científico poderia ocasionar à sociedade, em virtude do obscurantismo técnico, fomentado pelo cartesianismo (VASCONCELOS; FREITAS, 2012, p. 91).

Desse modo, consideramos que diferentes resultantes das relações CTS estão associados ao quadro de eventos associados à insustentabilidade, como componentes da crise ambiental. Então, na nossa compreensão, desenham-se convergências entre estes campos "Sustentabilidade e CTS", particularmente 
como objeto de estudo para o campo educacional. E assim, faz-se necessário empreender esforços para a compreensão dos aspectos envolvidos nessas convergências. Desse modo, o presente trabalho buscou compreender como se dá a inserção dos termos sustentabilidade e sustentável, em trabalhos de Teses e Dissertações (T\&D), que se caracterizaram como análise de práticas de Educação em Ciências/Educação Científica e Tecnológica de base CTS.

\section{Movimento metodológico}

A abordagem qualitativa, representada por um processo descritivo e analítico, nos termos de Oliveira (2014), constituiu nossa perspectiva metodológica. O processo metodológico de coleta de dados referiu-se ao desk research ${ }^{2}$, tendo como fonte de dados o Banco Digital de Teses e Dissertações (BDTD), do Instituto Brasileiro de Informação em Ciência e Tecnologia (IBICT).

O movimento de busca para a constituição dos dados de pesquisa se deu a partir dos seguintes passos: (1) seleção de T\&D, compreendendo o período de 2005 a 2015 e considerando o macro descritor CTS, em cujo resultado obteve-se 247 trabalhos; (2) escolha de trabalhos vinculados ao campo educacional, com 127 registros; posteriormente (3), seleção de trabalhos com a configuração de pesquisa-ação ${ }^{3}$, identificando-se 50 trabalhos (5 teses e 45 dissertações). Por fim, dentre esses 50 trabalhos, escolhemos aqueles que abordavam questões socioambientais, o que resultou em 35 textos, sendo 04 teses e 31 dissertações. Essa, então, constituiu-se nossa amostra de pesquisa.

Em um movimento subsequente, buscamos nessas 35 T\&D os seguintes descritores/termos: sustentabilidade e insustentabilidade, sustentável, sustentáveis, insustentável e insustentáveis. Em prosseguimento, procuramos identificar a natureza da presença desses descritores, enquadrando-os nas seguintes categorias: mencionado, descrito ou discutido. O processo analítico se deu sob a perspectiva interpretativa (ESTEBAN, 2010).

Cabe destacar, neste ponto, que, em trabalho anterior (FREITAS; MARQUES, 2017), consideramos dois conjuntos de T\&D: (1) aquele em que não se observou a presença dos descritores elencados, bem como (2) aquele que

2 Pesquisa de dados secundários.

3 Acreditamos que essa configuração de pesquisa apresenta experiências pedagógicas que buscavam, de algum modo, a partir dos seus resultados, transformar o cenário educacional, no sentido de contribuir para qualificação do ensino. 
fez menção aos termos. A análise desses conjuntos de T\&D foi conduzida, principalmente, no sentido de ponderar sobre a ausência ou mera menção dos descritores, a despeito de as T\&D tratarem de temas socioambientais, no contexto da abordagem CTS, no ensino de Ciências e Educação Científico Tecnológica, o que exigiria referências à (in)sustentabilidade. Agora, para fins deste artigo, e complementando o trabalho anterior, apresentamos algumas análises, no intuito de ganhar profundidade nas discussões, de dois outros conjuntos de T\&D, a saber: (1) aqueles que descrevem os termos/ conceitos elencados, bem como (2) aqueles que procederam a discussões envolvendo os termos.

\section{Compreensões relativas ao Desenvolvimento Sustentável: a dimensão social em evidência}

Nesta seção, buscamos apresentar e problematizar pressupostos, perspectivas, princípios, valores e/ou outros aspectos assumidos pelos autores de $\mathrm{T} \& \mathrm{D}$, como inerentes ao termo conceito sustentável, segundo a natureza da inserção estabelecida como "descrito". Inicialmente, temos a destacar que o termo sustentável associado ao termo desenvolvimento, ao configurar o conceito de Desenvolvimento Sustentável (DS), foi reproduzido em algumas T\&D, a exemplo dos trabalhos de Vasconcellos (2008) e Melo (2010), dissertação e tese, respectivamente, como é apresentado no Relatório de Brundtland, elaborado pela Comissão Mundial sobre Meio Ambiente e Desenvolvimento, já indicado anteriormente, como aquele capaz de "[...] satisfazer as necessidades das gerações presentes, levando em consideração as necessidades das gerações futuras" (COMISSÃO, 1991, p. 46).

Assim, com a mera indicação do conceito, nos dois trabalhos selecionados, os autores se eximiram de apresentar a " $[. .$.$] confluência de discursos dos mais$ variados e conflitantes sobre Desenvolvimento Sustentável [...] no contexto de um modelo produtivista-capitalista [...]" (FREITAS; MARQUES, 2017, p. 230), carecendo de problematização, no sentido, por exemplo, de considerar o cenário configurado pela crise ambiental. Há vários motivos para que se considere que a ideia de desenvolvimento sustentável seria controversa, destaca-se um destes motivos, a saber: 
[...] de forma mais implícita, ou indireta, conflita com a tese do 'decrescimento' ${ }^{4}$. Afinal, uma das dimensões essenciais do ideal do desenvolvimento continua a ser justamente o crescimento econômico. E isso não poderia estar mais explícito do que no oitavo Objetivo de Desenvolvimento Sustentável (ODS-8), estabelecido pela Agenda 2030, cujo enunciado é 'promover o crescimento econômico sustentado [...]' (VEIGA, 2017, p. 235).

A despeito dos aspectos acima arrolados, na análise da dissertação (VASCONCELLOS, 2008) e da tese (MELO, 2010), observamos a ampliação da compreensão sobre DS, ao agregarem novos/outros elementos. Vejamos alguns excertos:

[...] o desenvolvimento sustentável envolve outros aspectos além da preservação da natureza, como por exemplo, a distribuição de riquezas e [a atenção à] exclusão social (VASCONCELLOS, 2008, p. 70, destaques nosso);

[...] Então, o desenvolvimento sustentável não se restringe à preocupação ambiental: inclui ainda a solução de questões mais amplas, como o direito a todos à cidadania (VASCONCELLOS, 2008, p. 29, destaques nosso).

[...] O conceito de DS do relatório de Brundtland pressupõe [...] existência dos aspectos do meio ambiente sem os quais não poderemos satisfazer as necessidades humanas básicas. Se não mantivermos um padrão mínimo da qualidade da atmosfera, dos solos, dos recursos hídricos, a possibilidade de satisfazer as necessidades humanas básicas poderá ficar comprometida [...] garantir esses recursos naturais não se coloca como uma questão puramente econômica, mas de justiça social (MELO, 2010, p. 24, destaques nosso).

4 Defendido por Latouche (vide referência), decrescimento não se constitui um conceito, muito menos oposto simétrico do crescimento. Trata-se da defesa ao abandono do objetivo do crescimento ilimitado, perspectiva capitalista, sob a base de recursos naturais finita, com consequências danosas ao ambiente e, consequentemente, para a humanidade. Apresenta-se como slogan político que repele o objetivo de crescimento pelo crescimento. 
Entender o desenvolvimento sustentável sob a perspectiva da dimensão social, como fizeram Vasconcellos (2008) e Melo (2010), é ponderar sobre a necessidade de considerar as pessoas em primeiro lugar, como defendido por Sen e Kliksberg (2010). Nesse contexto, a maior preocupação volta-se ao bem-estar humano. Trata-se, portanto, de conferir ao processo de desenvolvimento uma maior racionalidade social, no sentido de distribuição igualitária de renda, de diminuição das diferenças entre ricos e pobres e, especialmente, de melhoria das condições de vida das sociedades (SACHS, 1986).

Ao considerarmos a dimensão social do desenvolvimento sustentável, estamos reconhecendo, ao mesmo tempo, que

[...] a sociedade de mercado transforma o pacto social em um contrato de compra e venda, que oblitera os valores humanos, produzindo desigualdades econômicas, sociais entre indivíduos, grupos e segmentos no âmbito interno das nações [...] (PORTO; GARRAFA, 2005, p. 111).

Nesse contexto também, ao não levarmos em conta a dimensão social do desenvolvimento sustentável, aceitamos "[...] a pobreza e a desigualdade como um dado natural [...] a separação entre a lógica do mercado e a lógica dos direitos humanos e da defesa da cidadania [...]" (CACCIA BAVA, 2002, p. 80). Em face da ilimitabilidade dos desejos e das aspirações humanas, temos que considerar que

[...] nunca há tudo para todos, mas essa condição em si natural (a natureza é finita) é exacerbada em sociedades que se concentram excessivamente as vantagens e oportunidades [sociedade capitalista]. Neste caso, trata-se de escassez produzida, mantida, cultivada [...] (DEMO, 1996, p. 7).

Assim sendo, não podemos desconsiderar a dimensão social do desenvolvimento sustentável, uma vez que para Tárrega e Perez (2007, p. 21),

O desenvolvimento sustentável engloba mais que crescimento econômico e proteção ambiental, ele é calcado também na idéia de eqüidade social e bem-estar, que constitui o seu terceiro pilar. Já foi reconhecido que tanto a pobreza como a riqueza extremas pressionam o meio ambiente. 
Portanto, ao se falar em desenvolvimento sustentável, deve-se considerar também o desenvolvimento social, afinal, é plenamente possível que o crescimento econômico coexista com a pobreza disseminada [mas não desejável]. Ademais, com o desenvolvimento social as pressões sobre o meio ambiente diminuem, na medida em que o uso sustentável dos recursos naturais auxilia a realização da eqüidade social.

Então, o desenvolvimento que se deseja sustentável “[...] requer que se removam as principais fontes de privação de liberdade: pobreza e tirania, carência de oportunidades econômicas e destituição social sistemática, negligência dos serviços públicos [...]" (SEN, 2000, p. 18), sem o que não podemos considerar desenvolvimento sustentável.

Vasconcellos (2008), em sua dissertação, avança na sua discussão ao afirmar que o DS pressupõe direito a cidadania. A definição de cidadania ainda hoje não se mostra consensual (BOTELHO; SCHWARCZ, 2012). Consideramos aqui uma compreensão de cidadania como um sentido objetivo de inclusão (MARSHALL, 1967), em face da agudização das desigualdades. Nesse contexto, trata-se de um desafio à sociedade em geral e, particularmente, aos educadores, principalmente na constituição de novos saberes para apreender processos sociais, que a cada dia se complexificam (JACOBI, 2005).

Por sua vez, ao considerarmos a complexidade de abordagem do tema inclusão, buscamos compreendê-la pelo seu oposto, justamente porque a questão da inclusão social está fortemente vinculada à exclusão social (FALEIROS, 2006). Nesse sentido, podemos destacar as observações de Bauman (2005, p. 47):

[...] a disfunção mais gritante e potencialmente explosiva da economia capitalista, está mudando da exploração para a exclusão [...] que hoje está na base dos casos mais evidentes de polarização social, de aprofundamento da desigualdade e de aumento do volume de pobreza, miséria e humilhação.

Neste ponto, corroboramos Vasconcellos (2008) ao ponderar que, para além das preocupações ambientais, há que se pensar em distribuição de riquezas e cidadania, aspectos associados à dimensão social do desenvolvimento que se deseja sustentável, no sentido de abolir as privações que importam em exclusão social. Melo (2010) também, em seu trabalho de tese, refere que o DS requer, a despeito da necessidade de conservação dos recursos naturais para os 
próprios fins econômicos, que o considere como uma questão de justiça social. De fato, a justiça tem relação com justa distribuição de recursos e oportunidades (RAWLS, 2016).

Assim, temos a destacar que os elementos sociais integrados ao entendimento de DS, presentes nos trabalhos de Vasconcellos (2008) e Melo (2010), são pertinentes e renovam a compreensão de DS. A própria Agenda 2030, por meio de seus objetivos de DS (17 objetivos), apresenta 10 objetivos vinculados à dimensão social do desenvolvimento ${ }^{5}$; os demais objetivos inserem-se na dimensão econômica (3 objetivos) $)^{6}$, ambiental ( 3 objetivos $)^{7}$ e política global (1

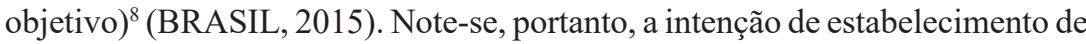
uma nova racionalidade (social) para o ideal do desenvolvimento sustentável.

Pode parecer incomum abordar questões que tratem da dimensão social do desenvolvimento sustentável na educação em ciências de base CTS, como, por exemplo, a exclusão social, a pobreza, a cidadania etc. Mas, entendemos que, ao assumir tal perspectiva, estaremos aproximando o social do natural, contribuindo para minimizar a subteorização de tais aspectos, particularmente quando se busca inter-relacionar Ciência e Tecnologia (C\&T), no contexto societário. Ademais, nos dias atuais, tais questões assim se configuram:

5 Objetivo1: Acabar com a pobreza em todas as suas formas, em todos os lugares; Objetivo 2: Acabar com a fome, alcançar a segurança alimentar e melhoria da nutrição e promover a agricultura sustentável; Objetivo 3: Assegurar uma vida saudável e promover o bem-estar para todos, em todas as idades Objetivo 4: Assegurar a educação inclusiva e equitativa de qualidade, e promover oportunidades de aprendizagem ao longo da vida para todos; Objetivo 5: Alcançar a igualdade de gênero e empoderar todas as mulheres e meninas; Objetivo 6: Assegurar a disponibilidade e gestão sustentável da água e o saneamento para todos; Objetivo 7: Assegurar a todos o acesso confiável, sustentável, moderno e a preço acessível à energia; Objetivo 10: Reduzir a desigualdade dentro dos países e entre eles, Objetivo 11: Tornar as cidades e os assentamentos humanos inclusivos, seguros, resilientes e sustentáveis; Objetivo 16: Promover sociedades pacíficas e inclusivas para o desenvolvimento sustentável, proporcionar o acesso à justiça para todos e construir instituições eficazes, responsáveis e inclusivas em todos os níveis.

6 Objetivo 8: Promover o crescimento econômico sustentado, inclusivo e sustentável, emprego pleno e produtivo e trabalho decente para todos; Objetivo 9: Construir infraestruturas resilientes, promover a industrialização inclusiva e sustentável e fomentar a inovação; Objetivo 13: Assegurar padrões de produção e de consumo sustentáveis.

7 Objetivo 13: Tomar medidas urgentes para combater a mudança do clima e os seus impactos; Objetivo 14: Conservar e usar sustentavelmente os oceanos, os mares e os recursos marinhos para o desenvolvimento sustentável; Objetivo 15: Proteger, recuperar e promover o uso sustentável dos ecossistemas terrestres, gerir de forma sustentável as florestas, combater a desertificação, deter e reverter a degradação da terra e deter a perda de biodiversidade.

8 Objetivo 17: Fortalecer os meios de implementação e revitalizar a parceria global para o desenvolvimento sustentável 
[...] temas a serem privilegiados no espaço da sala de aula, notadamente aqueles que dizem respeito às desigualdades sociais e ambientais, às carências de oportunidades sociais, aos conflitos socioambientais, entre outros. Essas questões se constituem [ou são consideradas meras] externalidades de um modelo de desenvolvimento fundamentado, basicamente, na perspectiva econômica do processo, mostrando-se socialmente injusto e ambientalmente insensato (VASCONCELOS et al., 2014, p. 251).

A sala de sala constitui-se um espaço social, no qual essas e outras questões necessitam ser abordadas, no sentido de abalar pensamentos para, por fim, favorecer ao "reagir" a esse estado de coisas, de modo a caminhar prospectivamente e positivamente na direção da transformação social.

\section{Sustentabilidade e CTS: o necessário diálogo no ensino}

Nesta seção, damos ênfase a uma das T\&D estudadas, cujas apreensões se apresentaram como inerentes ao termo conceito sustentável, segundo a natureza da inserção estabelecida como "discutido", o que propiciou ponderar sobre aspectos relevantes aos campos "Sustentabilidade e CTS". O excerto destacado revela a preocupação do autor com a adequada abordagem das relações CTS no ensino, em face da consideração da sustentabilidade. Vejamos o excerto:

Se como professor, opto por ensinar a respeito das possibilidades de a reciclagem dar um fim correto e sustentável para os resíduos produzidos sem abordar, por exemplo, o papel que podemos desempenhar na redução da produção desses resíduos, posso estar ensinando a favor de uma cultura do consumismo e do desperdício, aliada ao mito de que a tecnologia envolvida no processo de reciclagem no caso irá sempre propor uma solução [...] (PRUDÊNCIO, 2013, p. 36, destaque nosso).

Podemos avaliar como pertinente a reflexão do autor, ao considerarmos as ponderações semelhantes de Layrargues (2011, p.182-187), a saber:

Essa prática educativa, que se insere na lógica da metodologia da resolução de problemas ambientais locais de modo pragmático, tornando a 
reciclagem do lixo uma atividade-fim, ao invés de considerá-la um temagerador para o questionamento das causas e consequências da questão do lixo, remete-nos de forma alienada à discussão dos aspectos técnicos da reciclagem, evadindo-se da dimensão política.

Pensar a questão do descarte dos resíduos na natureza, como um dos grandes problemas para a sociedade, é evidenciá-la como reflexo de um modelo de "[...] desenvolvimento econômico-produtivista, que impulsiona e é impulsionado pelo consumo crescente e supérfluo" (FONSECA NETO; FREITAS; FREITAS, 2017, p. 136), cujo objetivo é transformar cada cidadão em um consumidor voraz e autômato. Mesmo porque, "[...] o fator organizador da sociedade contemporânea encontra-se na esfera do consumo e não da produção" (ZACARIAS, 2009, p. 119). Neste contexto, somos cativos da obsolescência programada e, portanto, subjugados à lógica de produção em massa e do descarte, em períodos cada vez mais reduzidos (ZANETI; SÁ; ALMEIDA, 2009). Tais situações configuram-se processos insustentáveis do atual modelo de desenvolvimento.

Segundo Feldmann (2005, p. 148), o “[...] problema não é o consumo em si mesmo, mas os seus padrões e efeitos". Se refletirmos bem “[...] nós é que somos consumidos pelo consumo. Somos atropelados desde o modo como os produtos são produzidos, divulgados, consumidos, descartados, sem mesmo nos darmos conta do seu custo social e ambiental" (GONÇALVES, 2011, p. 10); engendrados estamos "[...] na cultura do consumo, alienada e alienante" (FONSECA NETO; FREITAS; FREITAS, 2017, p. 138), representando discussão capital no âmbito da educação.

O desejo de consumir crescentemente é uma criação da sociedade líquido-moderna (BAUMAN, 2008). Tal construção é "produzida" no contexto de um sistema econômico produtivista, cuja (super)valorização se dá ao consumo desenfreado, fazendo incidir no imaginário coletivo a necessidade, por vezes patológica, do ter em detrimento do ser. Tal estado de coisas é um grande desafio à sustentabilidade (ZANIRATO; ROTONDARO, 2016), de modo que o desenvolvimento possa generalizar-se por meio da constituição de uma "civilização do ser", no compartir equilibrado do "ter" (SACHS, 2007).

Cabe destacar, neste ponto, outra preocupação apresentada por Prudêncio (2013), em sua tese, que, ao tratar o tema reciclagem sem a devida consideração das possibilidades de redução da produção de resíduos, poderia levar seus alunos a entender que a tecnologia tudo pode resolver. De fato, é comum às pessoas confiarem no poder da ciência e da tecnologia, entendendo que estas podem 
[...] resolver os problemas de qualquer natureza e ordem, tal qual aqueles que acreditam vigorosamente numa divindade [de modo que] [...] essas pessoas são levadas a pensar dessa maneira durante a sua permanência nos bancos escolares e, posteriormente, o seguem fazendo no trato de suas profissões (BAZZO, 2015, p. 55).

Considerar que a tecnologia, mais cedo ou mais tarde, possa solucionar os problemas que engendram, "como veneno e antídoto", constitui-se pensamento de risco, ao ponderarmos que "tais soluções" podem produzir outros/novos problemas e riscos.

Por fim, depreendemos que são pertinentes e importantes as reflexões/ preocupações apresentadas no trabalho de tese de Prudêncio (2013), na abordagem do tema reciclagem, dado que não se fundamentam em uma perspectiva ingênua, esvaziada da crítica dos valores culturais da sociedade do consumo, do consumismo e da tecnociência - por vezes vista como uma espécie de "poção mágica" que tudo pode resolver. Outros aspectos também poderiam ser agregados a essa crítica, como as perspectivas do desenvolvimentismo/industrialismo, da lógica perversa e degenerativa do capital, dos aspectos perniciosos da cadeia da reciclagem do lixo, entre outros aspectos que contribuem para a crítica ao consumo exacerbado e todos os seus desdobramentos (LAYRARGUES, 2011; ZANETI; SÁ; ALMEIDA, 2009).

\section{Considerações finais}

Reconhecemos que as preocupações ambientais, contemporaneamente, constituem-se o core das discussões relativas à (in)sustentabilidade, algo que pressupõe ponderar sobre os impactos irreversíveis da exploração degenerativa da natureza, principalmente sob a égide do capitalismo. Com o processo econômico, apoiado pela C\&T, exige-se abordagem, especialmente no âmbito educacional, em geral, e na educação em Ciências, em particular, na perspectiva da abordagem CTS.

Por outro lado, não podemos nos restringir a analisar somente uma das dimensões (a ambiental ou a econômica) dos processos que geram a insustentabilidade, sob o risco de adotarmos uma concepção reducionista e fragmentada, apartada de uma abordagem multidimensional da questão. Logo, a dimensão social da sustentabilidade (e próprio do desenvolvimento sustentável) precisa, 
peremptoriamente, ser considerada, mas apresenta-se subteorizada, enquanto vertente das análises sobre a geração de problemas e também como orientadora de práticas sociais mais sustentáveis.

Entendemos que, em termos gerais, a educação de base CTS pressupõe um tratamento crítico dos conteúdos e de temas de ensino, precisamente na sua multiplicidade de aspectos, de modo que o tema da sustentabilidade - com inserção nos campos social, econômico, ambiental, ético, entre outros - constitua-se referência forte na problematização das relações CTS e da crise ambiental. É na ambiência da sala de aula que a abordagem das relações CTS em articulação com as questões de (in)sustentabilidade, pode dar conta das insuficiências na problematização dos desdobramentos das relações CTS para o campo socioambiental.

Nesse contexto de insuficiências, há a necessidade de se problematizar tendências de supervalorização das respostas tecnológicas aos problemas ambientais, desconsiderando, por vezes, que é justamente nas demandas sociais - na maioria das vezes sem a sociedade ser ouvida - por mais ciência e mais tecnologias, que se geram e se constituem as condições para os passivos socioambientais. Isso é exemplificado por discussões que ficam centradas no comportamento individual das pessoas sobre consumo/consumismo, deixando de lado a problematização do cenário insólito estabelecido pelo padrão econômico (do modelo capitalista de produção, suas relações sociais e organização da vida), o qual gera a degeneração crescente da natureza. Portanto, essa dinâmica sociedade-economia-ambiente, traz reflexos importantes para o campo social na abordagem CTS, sob a ótica da sustentabilidade.

Com isso chama-se a atenção para a necessária abordagem multidimensional das relações CTS no ensino, o que implica na consideração da (in) sustentabilidade, em sua pluralidade. Trata-se, por exemplo, da observância de aspectos importantes, como o problema da ética e de políticas subjacentes ao atual modelo de desenvolvimento, da crítica ao individualismo em detrimento do coletivismo, do isolamento das ciências sociais em relação às ciências naturais, estas, ao serem consideradas como pertencentes a campos distintos, isentas das possibilidades de diálogos.

Considerando a vigência de uma crise ambiental, com todas as transformações deletérias impingidas a natureza, face às necessidades, às conveniências e aos desejos humanos, é imperativo realizarmos discussões sobre as reais possibilidades de estarmos caminhando para a nossa própria extinção, ao promover a exaustão dos recursos naturais, comprometendo a capacidade de regeneração e reprodução da vida no planeta. A humanidade enfrenta um desafio sem precedentes, pois o sistema natural não pode sustentar, por muito tempo, as demandas das atividades econômicas, com todos os seus desdobramentos. 
Nesse contexto, devemos pensar e construir uma relação mais apropriada entre os seres humanos e destes com a natureza. A Educação em Ciências e a Educação Científica e Tecnológica podem contribuir para isso, principalmente quando problematizam os eventos resultantes das relações CTS, pela ótica da sustentabilidade, explicitando os componentes associados à crise ambiental, revelando, assim, as convergências destes dois campos, Sustentabilidade e CTS. Considerar a (in)sustentabilidade no contexto da abordagem CTS, agrega qualidade social à educação, pois se constitui referência valiosa, notadamente na vigência de uma crise ambiental.

\section{REFERÊNCIAS}

BAUMAN, Z. Identidades: entrevista a Benedetto Vecchi. Rio de Janeiro: Jorge Zahar Ed., 2005.

BAUMAN, Z. Vida para consumo: a transformação das pessoas em mercadoria. Rio de Janeiro: Jorge Zahar Ed., 2008.

BAZZO, W. A. De técnico e de humano: questões contemporâneas. Florianópolis: Ed. da UFSC, 2015.

BOTELHO, A.; SCHWARCZ, L. M. Cidadania e direitos: aproximações e relações. In: BOTELHO, A.; SCHWARCZ, L. M. (Orgs.). Cidadania, um projeto em construção: minorias, justiça e direitos. São Paulo: Claro Enigma, 2012.

BRASIL. Transformando nosso mundo: a Agenda 2030 para o Desenvolvimento Sustentável. 2015. Disponível em: http://www.itamaraty.gov.br/images/ed_desenvsust/ Agenda2030-completo-site.pdf. Acesso em: 10 ago. 2018.

CACCIA BAVA, S. Mitos e realidades sobre inclusão social, participação cidadã e desenvolvimento local: uma discussão sobre contextos e conceitos. In: FORO TEMÁTICO REGIONAL. GOBERNABILIDAD PARA EL EMPODERAMIENTO LOS POBRES, 2, 2002, Lima. Disponível em: http://ftp.lna.br/users/mabans/misc/on_is/contexto.htm. Acesso em: 11 jan. 2018.

CAVALCANTI, C. Sustentabilidade: mantra ou escolha moral? Uma abordagem ecológico-econômica. Estudos Avançados, São Paulo, v. 26, n. 74, p. 35-50, 2012.

COMISSÃO MUNDIAL SOBRE O MEIO AMBIENTE E DESENVOLVIMENTO. Nosso futuro comum. Rio de Janeiro: FGV, 1991.

CORREIA, M. L. A.; DIAS, E. R. Desenvolvimento sustentável, crescimento econômico e o princípio da solidariedade intergeracional na perspectiva da justiça ambiental. 
Planeta Amazônia: Revista Internacional de Direito Ambiental e Políticas, Macapá, n. 8, p. 63-80, 2016.

DEMO, P. Pobreza política. Campinas: Autores Associados, 1996.

ESTEBAN, M. S. Pesquisa qualitativa em educação: fundamentos e tradição. Porto Alegre: Artmed, 2010.

FALEIROS, V. P. Inclusão social e cidadania. In: INTERNATIONAL COUNCIL ON SOCIAL WELFARE, 32, Brasília, 2006. Disponível em: https://www.icsw.org/images/ docs/Events/2006_Brazil/17_07_PDF/vicente_faleiros.pdf. Acesso em: 12 jan. 2018.

FAUSTINO, M.; AMADOR, F. O conceito de "sustentabilidade": migração e mudanças de significados no âmbito educativo. Indagatio Didactica, Aveiro, Portugal, v. 8, n. 1, p. 2021-2033, 2016.

FELDMANN, F. Meio Ambiente e consumismo. In: TRIGUEIRO, A. (Cord.). Meio Ambiente no século XXI: 21 especialistas falam da questão ambiental nas suas áreas de conhecimento. 4. ed. Campinas, SP: Armazém do Ipê. 2005. p. 143-157.

FERREIRA PIMENTA, M. F.; NARDELLI, A. M. B. Desenvolvimento sustentável: os avanços na discussão sobre os temas ambientais lançados pela conferência das Nações Unidas sobre o desenvolvimento sustentável, Rio+20 e os desafios para os próximos 20 anos. Perspectiva, Florianópolis, v. 33, n. 3, p. 1257-1277, 2015.

FONSECA NETO, S. N.; FREITAS, N. M. S.; FREITAS, N. M. S. Uma carta para o futuro: constructos sobre (in)sustentabilidade. Ciência e Natura, Santa Maria, v. 39, n. 1, p. 133-141, 2017.

FREITAS, N. M. S.; MARQUES, C. A. Abordagens sobre sustentabilidade no ensino CTS: educando para a consideração do amanhã. Educar em Revista, Curitiba, n. 65, p. 219-235, 2017.

GONÇALVES, P. A cultura do supérfluo: lixo e desperdício na sociedade de consumo. Rio de Janeiro: Garamond, 2011.

JACOBI, P. R. Educação ambiental: o desafio da construção de um pensamento crítico, complexo e reflexivo. Educação e Pesquisa, São Paulo, v. 31, n. 2, p. 233-250, 2005.

LATOUCHE, S. O decrescimento. Por que e como? In: LÉNA, P.; NASCIMENTO, E. P. Enfrentando os limites do crescimento: sustentabilidade, decrescimento e prosperidade. Rio de Janeiro: Garamond, 2012. p. 45-54.

LAYRARGUES, P. P. O cinismo da reciclagem: o significado ideológico da reciclagem da lata de alumínio e suas implicações para a educação ambiental. In: Loureiro, C. F. B.; LAYRARGUES, P. P.; CASTRO, R. S. (Orgs.). Educação ambiental: repensando o espaço da cidadania. São Paulo: Cortez, 2011. p. 185-226.

LEFF, E. Pensar a complexidade ambiental. In: LEFF, E. (Coord.). A complexidade ambiental. Tradução de Eliete Wolff. São Paulo: Cortez, 2010. p. 15- 64. 
MARQUES, C. A.; MACHADO, A. S. C. Environmental Sustainability: implications and limitations to Green Chemistry. Fundations of Chemistry, USA, v. 16, p. 125-147, 2014.

MARQUES, L. Capitalismo e colapso ambiental. Campinas, SP: Editora da Unicamp, 2015.

MARSHALL, T. H. Cidadania, classe social e status. Rio de Janeiro: Zahar Editores, 1967.

MELO, M. M. Capitalismo versus sustentabilidade: o desafio de uma nova ética ambiental. Florianópolis: Ed. da UFSC, 2006.

MELO, M. R. Elaboração e análise de uma metodologia de ensino voltada para as questões socioambientais na formação de professores de química. 2010. Tese (Programa de Pós-Graduação em Educação) - Universidade de São Paulo. São Paulo, 2010.

MORETTO, C. F.; GIACCHINI, J. Do surgimento da teoria do desenvolvimento sustentável à concepção de sustentabilidade: velhos e novos enfoques rumo ao desenvolvimento sustentável. Passo Fundo, RS: Universidade de Passo Fundo; Grupo Interdisciplinar de Estudos sobre Trabalho, 2006. (Texto para discussão $n^{\circ}$ 06). Disponível em: http://cepeac. upf.br/download/td_06_2006.pdf. Acesso em: 5 abr. 2018.

NASCIMENTO, E. P. do. Trajetória da sustentabilidade: do ambiental ao social, do social ao econômico. Estudos Avançados, São Paulo, v. 26, n. 74, p. 51-64, 2012.

OLIVEIRA, L. D. Os "limites do crescimento" 40 anos depois: das "profecias do apocalipse ambiental" ao "futuro comum ecologicamente sustentável”. Revista Continentes, Rio de Janeiro, n. 1, p. 72-96, 2012.

OLIVEIRA, M. M. Como fazer pesquisa qualitativa. 6. ed. Petrópolis: Vozes, 2014.

PORTO, D.; GARRAFA, V. Bioética de intervenção: considerações sobre a economia de mercado. Bioética, Brasília, v. 13, n. 1, p. 111-123, 2005.

PRUDÊNCIO, C. A. V. Perspectiva CTS em estágios curriculares em espaços de divulgação cientifica: contributos para a formação inicial de professores de ciências e biologia. 2013. Tese (Programa de Pós-Graduação em Educação) - Universidade Federal de São Carlos,. São Carlos, 2013.

RAWLS, J. Uma teoria da justiça. São Paulo: Martins Fontes, 2016.

SACHS, I. Espaços, tempos e estratégias de desenvolvimento. São Paulo: Vértice, 1986.

SACHS, I. Caminhos para o desenvolvimento sustentável. Rio de Janeiro: Garamond, 2002.

SACHS, I. Rumo à ecossocioeconomia. São Paulo: Cortez, 2007.

SEN, A. K. Desenvolvimento como liberdade. São Paulo: Companhia das Letras, 2000.

SEN, A. K.; KLIKSBERG, B. As pessoas em primeiro lugar: a ética do desenvolvimento e os problemas do mundo globalizado. São Paulo: Companhia da Letras, 2010. 
TÁRREGA, M. C. V.; PEREZ, H. L. A. A tutela jurídica da biodiversidade: a influência da convenção sobre a diversidade biológica no sistema internacional de patentes. In: TÁRREGA, M. C. V. (Coord.). Direito ambiental e desenvolvimento sustentável. São Paulo: RCS Editora, 2007. p. 29-30.

VASCONCELOS, E. R. et al. Educar para a justiça social e ambiental: que questões pensar no contexto do ensino e da formação de professores de ciências? Revista Brasileira de Pesquisa em Educação em Ciências, São Paulo, v. 14, n. 2, p. 245- 254, 2014.

VASCONCELOS, E. R.; FREITAS, N. M. S. O paradigma da sustentabilidade e a abordagem CTS: mediações para o ensino de ciências. Amazônia. Revista de Educação em Ciências e Matemáticas, v. 9, n. 17, p. 89-108, jul.-dez. 2012.

VASCONCELLOS, E. S. Abordagem de questões socioambientais por meio de tema CTS: análise de prática pedagógica no ensino médio de química e proposição de atividades. 217 f. 2008. Dissertação (Programa de Pós-Graduação em Ensino de Ciências) - Universidade de Brasília. Brasília. 2008.

VEIGA, J. E. O principal desafio do século XXI. Ciência e Cultura, Campinas, São Paulo, v. 57, n. 2, p. 4-5, 2005.

VEIGA, J. E. Desenvolvimento sustentável. O desafio do século XXI. Rio de Janeiro: Garamond, 2008.

VEIGA, J. E. Para entender o desenvolvimento sustentável. São Paulo: Editora 34, 2015.

VEIGA, J. E. A primeira utopia do antropoceno. Ambiente \& Sociedade, São Paulo, v. 20, n. 2, p. 227-246, 2017.

ZACARIAS, R. "Sociedade de Consumo", ideologia do consumo e as iniquidades socioambientais dos atuais padrões de produção e consumo. In: LOUREIRO, C. F. B.; LAYRARGUES, P. P.; CASTRO, R. S. (Orgs.). Repensar a educação ambiental: um olhar crítico. São Paulo: Cortez, 2009. p. 119-139.

ZANETI, I. C. B.; SÁ, L. M.; ALMEIDA, V. G. Insustentabilidade e produção de resíduos: a face oculta do sistema do capital. Sociedade e Estado, Brasília, v. 24, n. 1, p. 173-192, 2009.

ZANIRATO, S. H.; ROTONDARO, T. Consumo, um dos dilemas da sustentabilidade. Estudos Avançados, São Paulo, v. 30, n. 88, p. 77-92, 2016.

Texto recebido em 15/07/2019.

Texto aprovado em 11/09/2019. 